\title{
Recurrent squamous odontogenic tumor: A case report and review of the literature
}

\author{
BARBARA MOHR $^{1}$, JOCHEN WINTER ${ }^{2}$, GERHARD WAHL $^{1}$ and EMILIA JANSKA ${ }^{3}$ \\ ${ }^{1}$ Department of Oral Surgery; ${ }^{2}$ Oral Cell and Tumor Biology Group, Department of Periodontology, \\ Operative and Preventive Dentistry, University Hospital Bonn, Bonn D-53111, Germany; \\ ${ }^{3}$ Department of Stomatology and Maxillofacial Surgery, Comenius University, \\ Bratislava 81101, Slovak Republic
}

Received September 9, 2014; Accepted June 11, 2015

DOI: $10.3892 / 01.2015 .3632$

\begin{abstract}
Squamous odontogenic tumors (SOTs) are benign, locally infiltrative neoplasms that localize to the periodontium. In total, $<50$ cases have been reported since the first description of SOTs in 1975. Although the exact etiology of SOTs is unknown, the tumors are considered to derive from the epithelial cell rests of Malassez. SOTs are characterized by radiological and clinical signs and symptoms, including pain with increased sensitivity in the affected area, bone expansion and increased tooth mobility. The present study describes the case of a patient that experienced numerous SOT recurrences and also discusses recommendations for treatment. A locally invasive mandibular SOT was identified in a Caucasian 41-year-old female patient. The treatment involved recommended conservative surgery, including local curettage. In addition, 49 cases published in the literature were reviewed to assess the treatment strategies. The present patient experienced two recurrences of the tumor during the 6-year follow-up period. Ultimately, the vitality of the adjacent teeth was compromised. An apicoectomy with a small amount of resection of the marginal bone was necessary. In $>50 \%$ of the reported cases of SOT in the literature the adjacent teeth were extracted. The present case of SOT and the associated literature were also discussed. It was concluded that the treatment of choice appears to be a conservative surgical removal, but the successful management of SOTs often requires the removal of the adjacent teeth.
\end{abstract}

\section{Introduction}

The interest in odontogenic tumors has considerably grown since the first edition of the World Health Organization

Correspondence to: Dr Barbara Mohr, Department of Oral Surgery, University Hospital Bonn, 17 Welschnonnenstraße, Bonn D-53111, Germany

E-mail: barbara.mohr@ukb.uni-bonn.de

Key words: tumor of the periodontium, squamous odontogenic tumor, recurrence, treatment recommendations
(WHO) tumor classification published in 1971 (1). A novel and completely revised WHO classification from 2005, which encompasses the histopathological and genetic criteria of SOTs, describes a group of epithelial odontogenic tumors that comprises the ameloblastoma family, consisting of solid/multicystic, extraosseous/peripheral, desmoplastic and unicystic ameloblastoma, and squamous, adenomatoid, calcifying and keratocystic odontogenic tumors (2).

Squamous odontogenic tumors (SOTs) are rare benign tumors of the periodontium that possess an unknown etiology and were first described in $1975(3,4)$. In the literature, $>50$ cases have been reported (5). SOTs are slow-growing, locally infiltrating tumors with only a few clinical signs and symptoms. Indicators for the underlying tumor include mobility of the teeth, increased periodontal pocket depth, sensitivity, swelling and erythema of adjacent gingiva, swelling of the alveolar process, and moderate pain (5-7). SOTs have also been reported to occur in various age groups, yet mainly affect adults in the third decade of life (8). The male to female gender ratio is 1.4:1 (5). The mandible is affected more often than the maxilla, with a preferential occurrence in the posterior premolar and molar area. Maxillary SOTs are described to be primarily present in the anterior area, and appear to be more aggressive compared with SOTs in the mandibular area $(9,10)$. Multifocal lesions have been reported to be more frequent in these regions compared with other odontogenic tumors (11).

SOTs are hypothesized to derive from the epithelial cell rests of Malassez. These tumor entities usually appear on the lateral root surface. The typical radiographic presentation is a triangular radiolucent defect involving the lateral root surface of erupted and vital teeth (12). The wide base of the radiolucency is localized between the diverging apices of the adjacent roots (13). The most common variant of SOTs is an intraosseous or central type. However, a rare peripheral variant has also been described (14-17).

SOTs consist of islands of well-differentiated squamous epithelial cells of varying sizes and shapes, surrounded by mature connective tissue (9). An epithelial hamartomatous proliferation may also be suspected. As a result, this lesion is often described as a benign epithelial odontogenic tumor, acanthomatous ameloblastoma, acanthomatous ameloblastic fibroma or occasionally, well-differentiated squamosus cell 
carcinoma or pseudoephiteliomatous hyperplasia (7). A histopathological misinterpretation may therefore lead to either therapeutic over- or under-treatment. The prognosis of SOT therapy is good. Recurrence appears to be rare, and may occur due to incomplete tumor removal.

In the present study, the clinical, radiographic and histological characteristics of the squamous odontogenic tumor with locally invasive growth and two recurrences were reported for six years subsequent to the primary surgical removal. Subsequently, the known literature on treatment recommendations for SOT was critically reviewed.

\section{Case report}

A 41-year-old woman presented to a general dentist (Frechen, North Rhine-Westphalia, Germany) with unusual sensitivity and slight pressure on the left premolar side of the mandible in December 2006. The first panoramic radiograph did not reveal any changes in the bone. However, the patient repeatedly presented with the same complaint. Subsequent examination with a small periapical radiograph revealed a radiolucent lesion located between the roots of the canine and the first premolar in the left mandible. The patient was then referred from a general dentist to the Department of Oral Surgery at University Hospital Bonn (Bonn, Germany) for additional evaluation in January 2006.

Intraoral examination revealed small hard tissue swelling, termed osseous expansion, on the lingual aspect of teeth 21 and 22 (Fig. 1A). No hypoesthesia, hyperesthesia or anesthesia of the left inferior alveolar nerve was present. No signs of tenderness, purulence or hemorrhage were observed, and the patient did not suffer from any pain. The teeth were evaluated for vitality using refrigerant spray, consisting of a butane, propane and isobutane mixture (Kältespray PluLine $200 \mathrm{ml}$ Ds; Pluradent, Offenbach, Germany) and were deemed vital. The previous medical and surgical histories of the patient were completely negative; no tumors had been identified previously and the patient had not undergone any surgical procedures. Furthermore, the adjacent teeth were healthy. A panoramic and periapical radiograph revealed a triangular radiolucent lesion between the lower left canine and the first premolar, with the base of the radiolucency localized between the diverging apices of the adjacent roots (Fig. 1B). Based on these findings, the clinical diagnosis for the present patient was an odontogenic cyst, with the differential diagnosis being an epidermoid cyst or a keratocyst.

At the time of the procedure, visible soft swelling from the buccal side of teeth 21 and 22 was observed, and therefore, a vestibular approach to the lesion was used. The aim of the surgical procedure was to completely remove the lesion and perform curettage of the bony margins under local anesthesia. Shortly following the creation of marginal incisions and reflection of a mucoperiosteal flap, a vestibular bony wall perforation was identified, with the lesion visible underneath (Fig. 1C). The lesion was firm. Complete enucleation of the lesion was performed while preserving the lingual bony wall of the mandible. The root apices of the adjacent teeth extending to the lesion cavity were irrigated with sterile saline. The post-operative cavity was filled with a collagen sponge (TissuFleece E; Resorba
Table I. Post-operative intervals between follow-ups in the present patient and the corresponding clinical procedures and treatments for recurrence of SOT.

\begin{tabular}{lcc}
\hline $\begin{array}{l}\text { Post-operative } \\
\text { interval, months }\end{array}$ & $\begin{array}{c}\text { Procedure or } \\
\text { examination }\end{array}$ & $\begin{array}{c}\text { Diagnosis or } \\
\text { treatment }\end{array}$ \\
\hline 0 & 1st surgery & SOT removal \\
6 & Routine examination & NAD \\
12 & Routine examination & NAD \\
20 & 2nd surgery & Removal of \\
& Routine examination & NAD recurrence \\
26 & Routine examination & NAD \\
32 & Routine examination & NAD \\
38 & Routine examination & NAD \\
44 & CBCT, 3rd & No pathological \\
50 & surgery & abnormality \\
& Routine examination & NAD \\
56 & 4th surgery & Removal of SOT \\
62 & Apicoectomy & Pulpitis treatment \\
65 & Routine examination & NAD \\
72 & & \\
\hline
\end{tabular}

NAD, no abnormality detected.

GmbH, Nuremberg, Germany) and Penicillin G in powder form (Hydracillin; GlaxoSmithKline Biologicals, Dresden, Germany) to prevent additional collapse of the buccal area. The patient also received Phenoxymethylpenicillin at a dose of 1.5 million international units three times a day orally for one week (Penicillin V 1.5 Mega; Heumann Pharma GmbH, Nuremberg, Germany).

Histopathological examination was performed on the specimen, and the presence of fragments of a cystic lesion with a multilayered and variable well-differentiated epithelium was revealed. These demonstrated a tendency for flat squamous/epithelial differentiation. In wide regions the peripheral layer exhibited a cylindroepithelial configuration with adenoid segments. Smaller sections were two or three-layered, with evidence of calcified material (Figs. 2 and 3). The diagnosis of SOT was confirmed by the Bone Tumor Reference Center at the Institute of Pathology, University Hospital Basel (Basel, Switzerland).

Follow-up was performed every 6 months up to 72 months (Table I) and consisted of oral examinations and periapical radiographs. The X-rays revealed gradual bone recovery. Teeth 21 and 22 each remained vital, with light disturbance of sensitivity in the innervations of the left inferior alveolar nerve for $\sim 3$ weeks. The patient exhibited no symptoms, with the exception of a small painless osseous expansion on the lingual aspect of teeth 21 and 22 .

However, 1 year and 8 months subsequent to primary surgical treatment, routine X-ray examination revealed tumor recurrence (Fig. 4). At approximately the same time, the patient started to complain of pressure in the surgically resected region. 
A

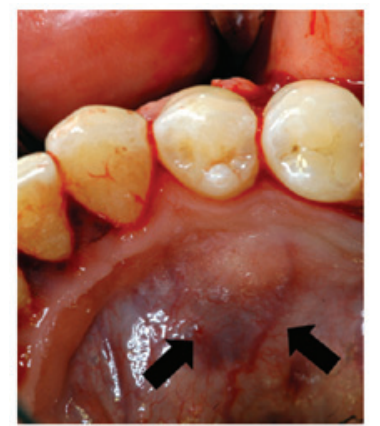

B

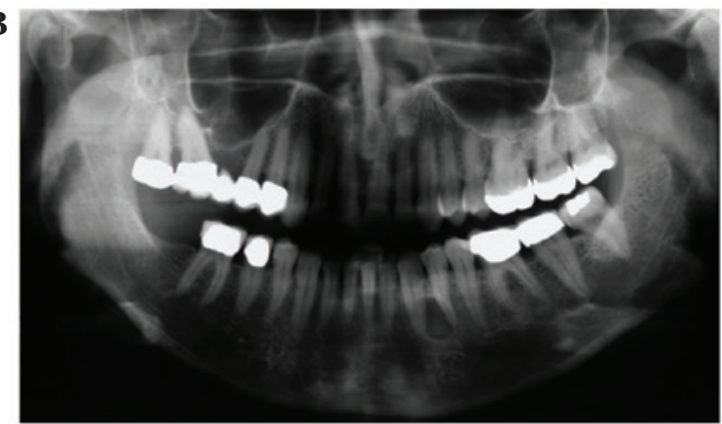

C

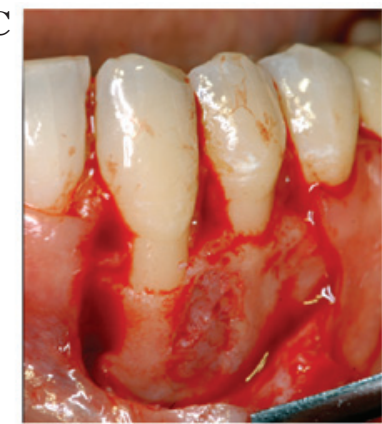

Figure 1. (A) Lingual osseous expansion in the lingual aspect of teeth 21 and 22. (B) Panoramic radiograph revealing the triangular radiolucent lesion between the roots of teeth 21 and 22, with the base of the radiolucency localized between the diverging apices of the adjacent roots. (C) Visible perforation of the vestibular bony wall subsequent to reflecting the flap.

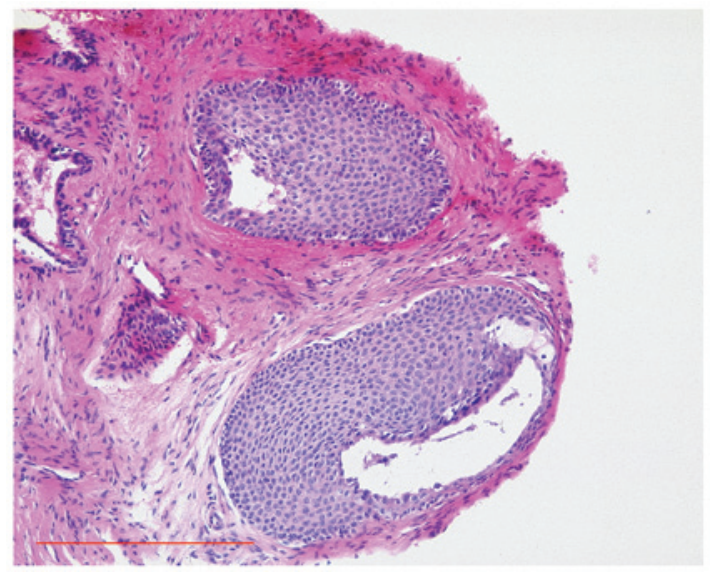

Figure 2. First image of the histopathological examination of the squamous odontogenic tumor. The examination revealed highly differentiated odontogenic epithelial cells forming oval islands, with a peripheral layer of low cuboidal epithelial cells and signs of microcystic degeneration (stain, hematoxylin and eosin; magnification, x200; scale bar, $200 \mu \mathrm{m}$ ).

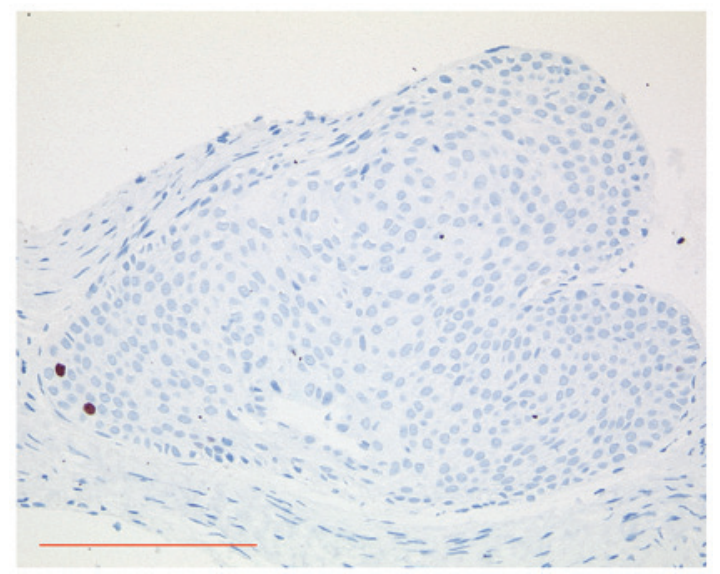

Figure 3. Second image of the histopathological examination, revealing low level expression of Ki67 in a small number of tumor cells, indicating minor mitotic activity (stain, Ki67; magnification, x400; scale bar, $100 \mu \mathrm{m}$ ).

A second surgical procedure revealed that the recurrent tumor was smaller, located only intraradicularly, and that the lesion did not extend to the root apices.

The procedure was performed under local anesthesia. A vestibular approach to the lesion was chosen. Two specimens were excised by curettage, consisting of the recurrent tumor (Fig. 5A) and a small cementoma-like tissue (Fig. 5B). The cavity was subsequently filled using a TissuFleece E collagen sponge. The vestibular defect was then covered with a BioGide membrane (Geistlich Pharma AG, Wolhusen, Switzerland) to prevent additional collapse of the buccal region.

The histological features observed were similar to those found in the sample, revealing segments of sclerotic stroma and segments of cystic structure, the previous composed of multilayered epithelium, with signs of squamous/flat-epithelial differentiation, or in other segments, cylindroepithelial differentiation. Numerous sections were formed by cuboidal epithelial cells. The second specimen revealed a small cementoma.

The patient underwent regular follow-ups every 6 months, with no clinical symptoms and no complaint about any pressure or sensitivity disturbances in the affected area (Table I) $(4,6,8,10,12-49)$. The two teeth 21 and 22 remained vital. A periapical radiograph revealed radiolucent changes in the surgical region 2 years and 6 months subsequent to the first recurrence. A cone beam computed tomography (CBCT) was performed shortly thereafter (Fig. 6).

According to the precise $\mathrm{CBCT}$ assessment, the vestibular bone between teeth 21 and 22 had been completely rebuilt. A round shaped radiolucent area $\sim 3 \mathrm{~mm}$ at the level of the middle third of tooth 33. Lingual bone expansion caused by the tumor was visible.

The surgical procedure was planned with an approach from the lingual aspect being considered. The aim was for a radical procedure that retained the vital teeth. The lingual osteotomy of teeth 21 and 22 revealed an empty cavity void of fluids or tissues. No pathological specimens were excised. Any superficial irregularities of the bone were subsequently removed. The surgical region was sutured.

The follow-up 6 months later revealed no clinical or radiological abnormalities. However, 12 months subsequent to the third procedure, the patient complained of pressure in the surgical region again. The teeth remained vital.

A novel lesion $\sim 7 \times 7 \mathrm{~mm}$ in size, identified on an X-ray performed at the general dentist, was removed from the vestibular side, followed by curettage of the bone according to recommendation from the Bone Tumor Reference Center at the Institute of Pathology, University Hospital Basel. The 


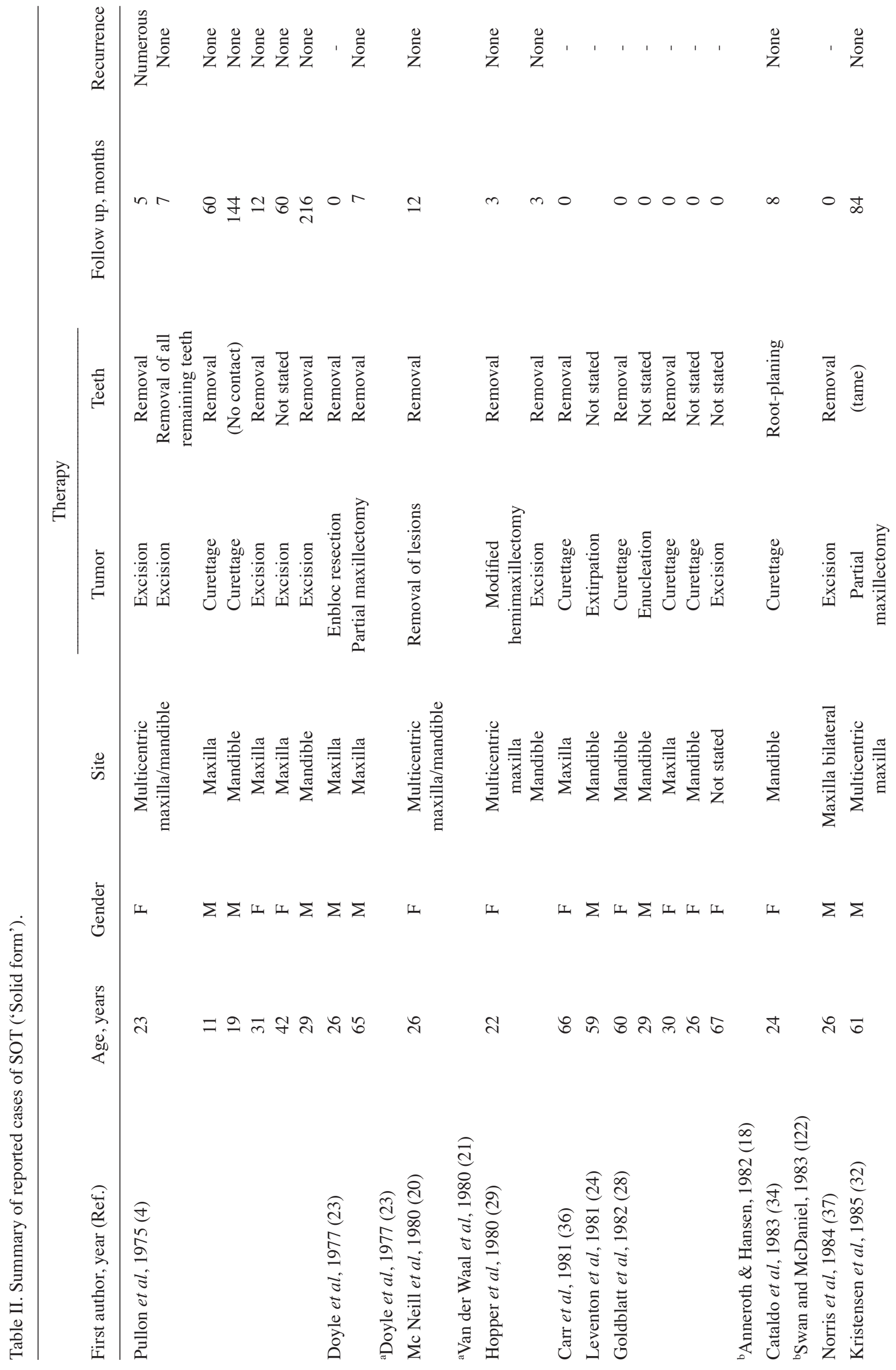




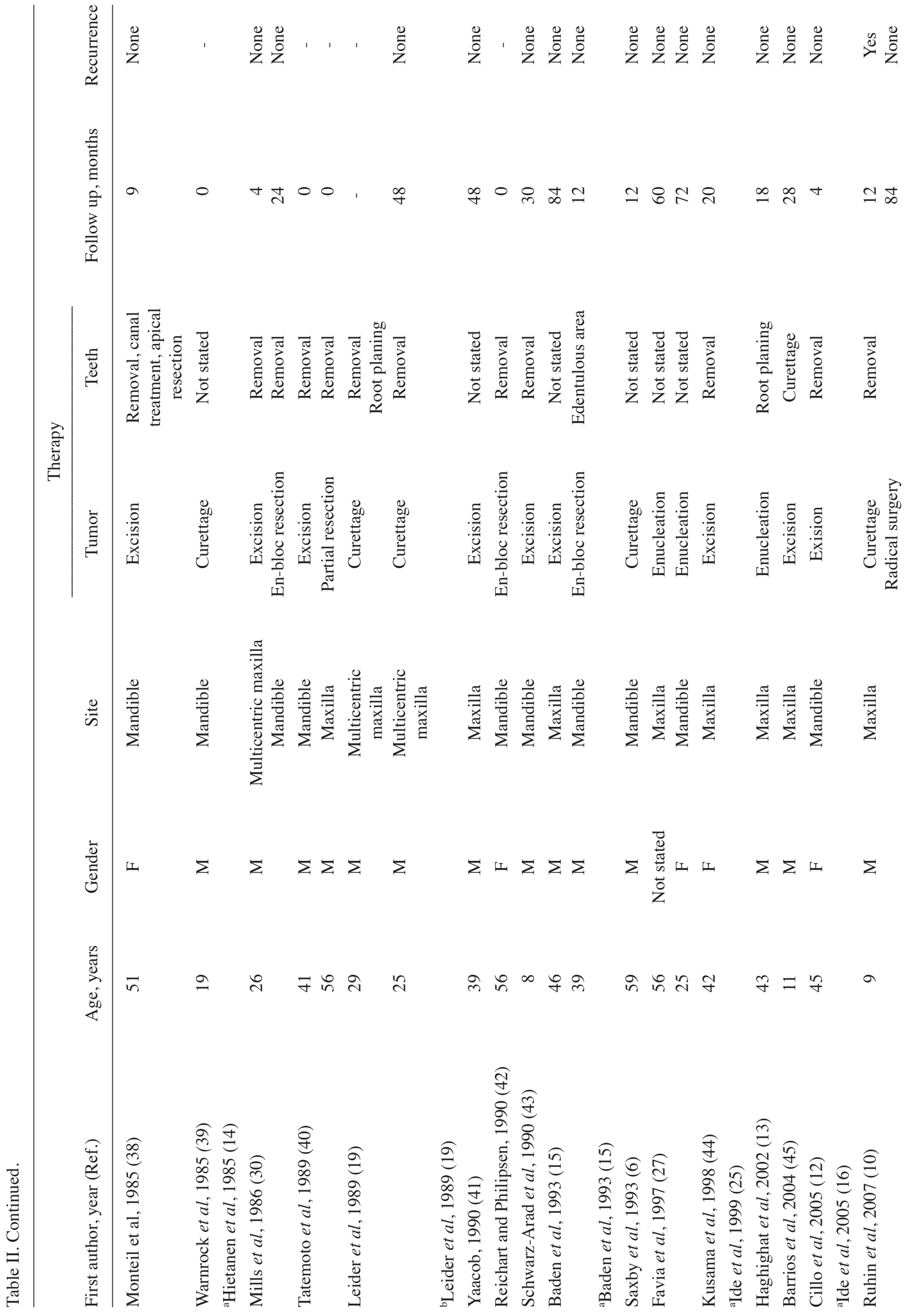




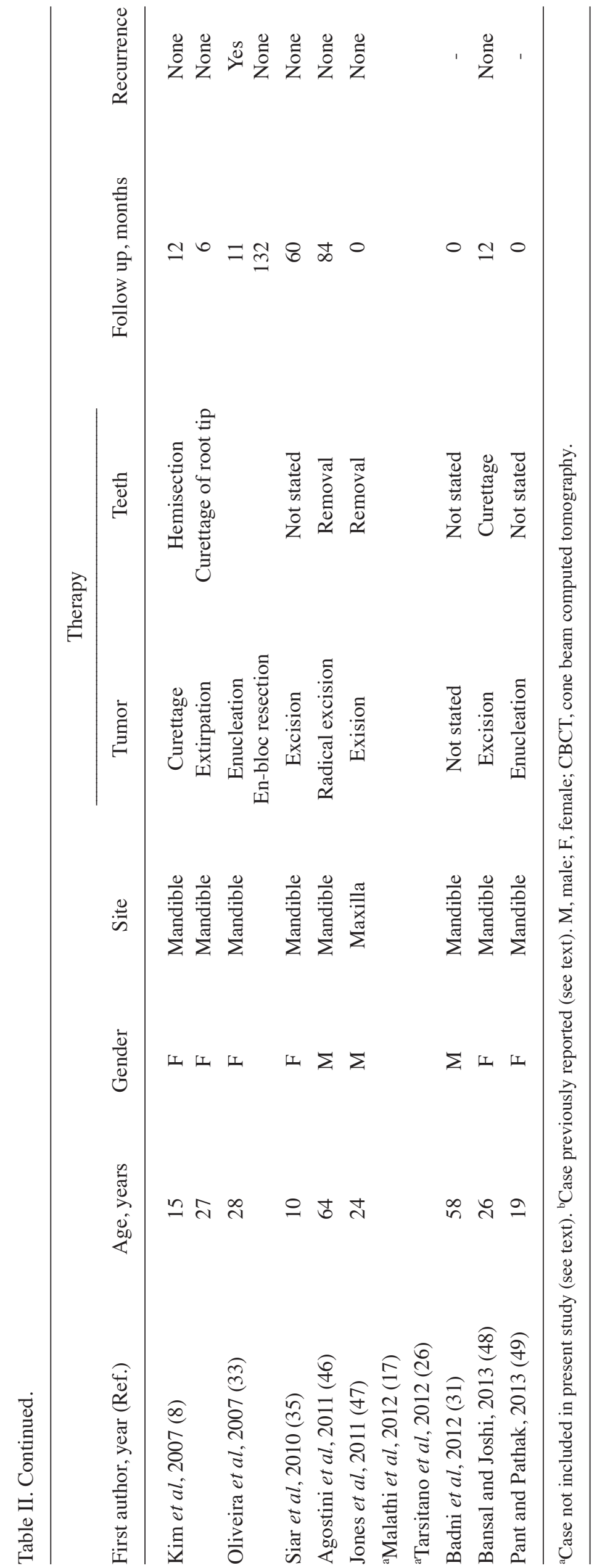




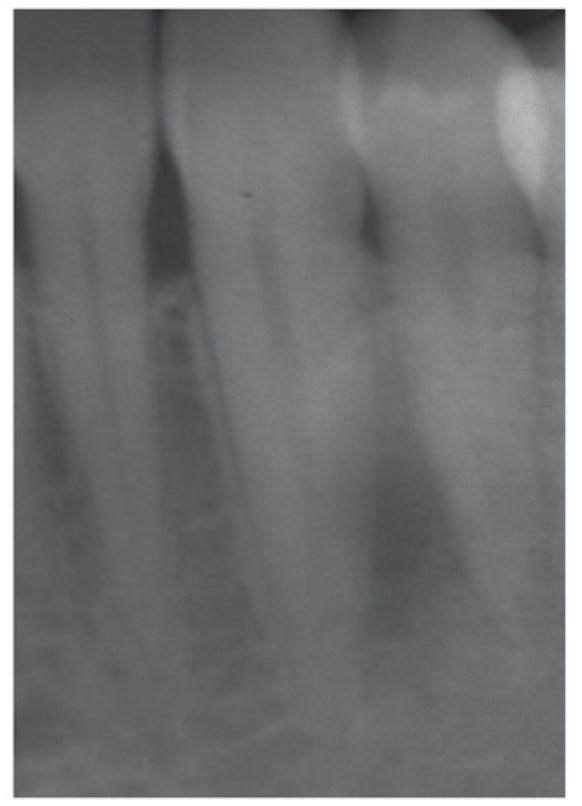

Figure 4. Periapical radiograph performed subsequent to the first recurrence revealing an interradicular osteolysis.

A

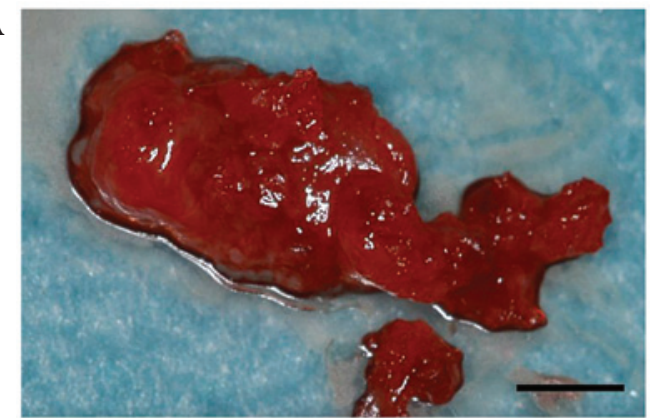

$\mathbf{B}$

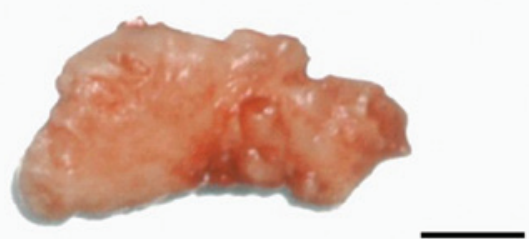

Figure 5. Two different tissues from the same lesion. (A) Squamous odontogenic tumor tissue and (B) cementoma-like sample (scale bars, $2 \mathrm{~mm}$ ).

patient began to exhibit disturbances and pulpitis-like symptoms 12 weeks subsequent to the fourth procedure that affected teeth 21 and 22. An apicoectomy with minimal resection of the marginal bone was then performed. The histological examination did not reveal any indication of recurrence of SOT. No squamous epithelium was observed. The sample consisted mainly of collagen connective tissue in addition to bony fragments. The healing of the wound was without complication, and the follow-up was performed every 6 months until May 2013, and revealed no pathological findings.

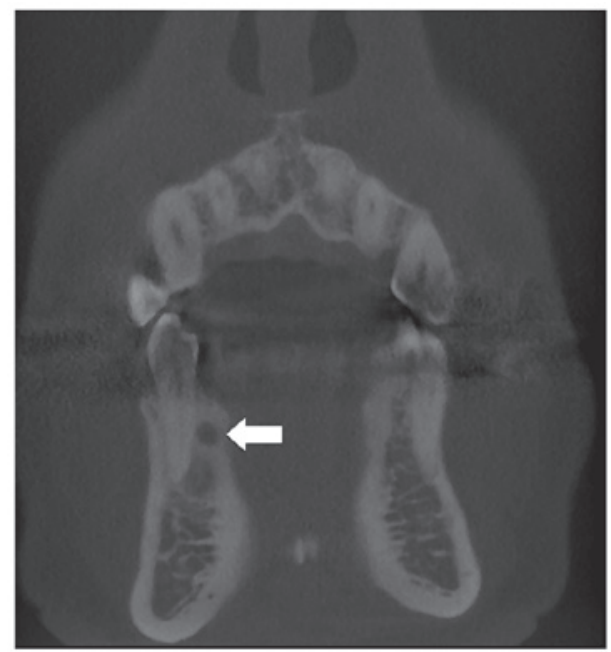

Figure 6. Cone beam computed tomography examination. The arrow indicates a lingual osteolytic space.

\section{Discussion}

Review of the literature for the solid-form of the SOT was performed using PubMed (National Center for Biotechnology Information, US National Library of Medicine, Bethesda, MD, USA) with the search combination 'squamous odontogenic tumor and recurrence'. The search was limited to the English literature. In total, 49 cases of this tumor were reported in English language journals (Table II), 7 of which were excluded for the following reasons: Anneroth and Hansen (18), previously reported by Pullon et al (4); Leider et al (19), previously reported by McNeill et al (20); Van der Waal et al (21), lesion diagnosed as a 'possible SOT'; Swan and McDaniel (22), the diagnosis was questionable; Doyle et al (23), reported SOT-like proliferations in odontogenic cysts; Leventon et al (24), reported SOT-like proliferations in odontogenic cysts; Ide et al (25), reported an intraosseous cell carcinoma arising in association with a SOT; and Tarsitano et al (26), reported a multifocal epithelial odontogenic tumor associated with a SOT.

In the literature, 4 studies reported examples of peripheral SOT (14-17). The age at the time of initial diagnosis ranged between 8 and 67 years, with a mean age of 36.3 years. The majority of SOTs become visible in patients aged 20-29, with 17 patients $(35 \%)$ in this age group.

The gender ratio from the 49 patients reported in the literature for whom this information was provided, including the present patient, is 1:1.2 (female:male). The study by Favia included no gender information (27). SOT occurred individuals of Caucasian, African and Asian descent, and predominance in a specific ethnicity was not observed.

The mandible was involved in $57.1 \%$ of all cases and the maxilla in only $38.8 \%$. In total, 8 patients exhibited multicentric lesions of the tumor, 4 of which involved maxillary and mandibular sites and 4 of which involved only a maxillary site. In 1 study the site was not stated (28).

At present, the treatment of 50 patients with solid SOTs has been described, including the present patient. The varying clinical behavior of the sites of multicentric lesions has also been reported $(29,30)$. In 1 study, information on the treatment 
administered was not included (31). In summary, 43 lesions were treated with conservative surgery, consisting of curettage, excision and enucleation, and 8 lesions were treated with radical surgery, consisting of en-bloc resection, modified hemimaxillectomy and partial maxilloectomy (Table II).

In total, 3 studies reported lesions detected in edentulous areas $(4,15,32)$. In all previous studies in the literature, the tumor was in contact with the surface of a tooth or teeth. In $>50 \%$ of cases, the adjacent teeth were extracted (Table II). In 1 case, a hemisection of the remaining tooth was performed (8).

Substantial follow-up data was not available in the literature. Follow-up times were reported in 33 studies for 49 patients, and ranged between a few weeks and a maximum of 216 months (Table II).

In total, 4 cases of recurrence have been reported in the literature $(4,10,28,33)$. Recurrence developed over a short period (7-12 months) in 2 cases subsequent to simple conservative treatment, without the removal of teeth $(10,33)$. Recurrence developed subsequent to surgery with incomplete removal of the adjacent teeth in 1 case (4). A second surgical procedure was performed in all cases, which included the removal of all remaining teeth. No additional recurrence was reported in any of these cases. Goldblatt et al (28) also reported the development of a recurrent lesion, with well-demarcated triangular radiolucency of the molar roots. Only a simple curettage was performed for this patient and no follow-up time was provided

According to the present literature review, the incidence of SOT is low. The female to male ratio (ratio, 1:1.2) in the present study was higher compared to the ratio reported in the study by Reichart (ratio, 1:1.4) (5). The tumor usually grows slowly and often demonstrates a lack of symptoms for a long time. The clinical and radiographic features of SOT are neither unique nor sufficient for diagnosis and this type of tumor may be confused with a number of other pathologies (33). Therefore, distinctive clinical, radiological and histological aspects are necessary for avoiding a misdiagnosis that may result in serious negative implications for the patient (25).

SOT may occur at any age, with predominance in the third decade. The youngest patient reported in the literature was a 9-year-old boy with maxillary SOT that was treated with local surgical tumorectomy. However, 10 months subsequent to the procedure, an extremely aggressive recurrence had to be treated by radical surgery (10). The maxilla appears to be involved more often in the region of the incisors, whereas the premolar and molar areas appear to be more involved in the mandible.

Even though SOT is a benign lesion, it should be considered as semi-malignant in certain cases, particularly in the maxilla, where SOTs demonstrate increased aggressiveness (10). The 41-year old female patient in the present study was first treated with enucleation of the tumor and surgical curettage while maintaining the involved vital teeth. Follow-up performed every 6 months revealed early stage small recurrences that could be immediately surgically treated. SOT is a slow growing tumor. The treatment recommendation of the WHO is conservative surgical intervention (5). However, the present study also revealed that a conservative approach, such as enucleation and simple curettage with the intent of preserving the vitality of involved teeth, may not be sufficient to prevent recurrence, but a more aggressive treatment is required. The patient returned for a regular follow-up 2 years and 6 months subsequent to the second surgical treatment, and did not exhibit any clinical symptoms, although CBCT revealed an abnormality lingual of tooth 22 (Fig. 5). However, no second recurrence was detected intraoperatively. One year later, a third lesion was removed followed by apicoectomy. Additional recurrence may lead to the decision of a radical surgical procedure with loss of the adjacent teeth. Compromised surgical therapy was performed due to the desire of the patient to preserve the teeth (Table I). The data from the literature has also indicated that curettage and extraction of the adjacent teeth has acted as an adequate therapy. Pullon et al (4) also described numerous recurrences following the completion of simple curettage with incomplete removal of the adjacent teeth. Goldblatt et al (28) reported a recurrent lesion with well-demarcated triangular radiolucency of the roots of the first and second molars. Although this previous study concluded that the excision and extraction of the involved teeth is an adequate treatment in the majority of cases, a simple curettage was performed. Follow-up data was not provided. Ruhin et al (10) and de Oliveira et al (33) described the development of recurrence following simple curettage. Subsequent to the removal of the remaining teeth, the patients were tumor-free during a long follow-up period. However, there are two cases in the literature where the post-operative radiograph revealed similar appearances, of triangular-shaped radiolucency, between the remaining teeth compared with the pre-operative film $(6,34)$. Therefore, these studies indicate that tumor recurrence cannot be excluded based on radiograph results alone.

It may be of clinical relevance to establish individual treatment plans to adequately respond to the biological behavior of these rare tumors.

SOT presents as a locally infiltrative neoplasm and has been known to infiltrate into adjacent tissues, with resorption of the alveolar bone and invasion of the overlying gingival and oral mucosa (2). In 2007, Kim et al (8) initially described a lesion associated with the erosion of the lingual cortical plate in the mandible in two cases of female patients aged 15 and 27 years. Until then, the perforation of the cortical bone has only been presented in the maxilla, where the bone is much thinner compared with the mandible and less resistant to erosion. In the present study, the case of a patient with buccal bone erosion of the mandible that was uncovered intraoperatively is reported. The lingual bone possessed a complete cortical layer, but with visible bone expansion.

The etiology of SOT has yet to be elucidated. However, immunohistochemical evaluation performed in a previous study revealed positive reactivity of varying intensity in the neoplastic epithelial cells for the Notch1, Notch2 and Notch 3 transmembrane receptors and their ligands. These findings suggest that these receptors play a role in the cytodifferentiation of SOTs (35).

Although SOTs are considered to be benign neoplasms, the behavior and local expansiveness of the tumor indicates the possibility of carcinomatous transformation. In 1999, Ide et al (25) first reported a rare occurrence of intraosseous squamous cell carcinoma arising in association with squamous odontogenic tumors. The enucleated specimen of the tumor, which was attached to an impacted third molar of the mandible, revealed a characteristic pattern of SOT. However, 
within 2 months, aggressive bone destruction exhibiting the typical findings of intraosseous squamous carcinoma was identified. It is questionable whether in the aforementioned case the squamous carcinoma arose de novo or presented a misleadingly benign appearance. However, the extensive assessment of specimens provided support to the hypothesis of the malignant alteration of SOT. The present study revealed that an odontogenic tumor, which is difficult to access, is prone to the development of recurrence (Table I). This may be due to the inability of the surgical treatment to fully remove all tumor cells from the tooth.

In summary, the potential for recurrence developing in even benign SOTs may depend on the accessibility of the SOTs for surgical treatment and the biological behavior of the SOTs. The present study recommends an individualized treatment plan in order to respond to the biological reaction of the SOT rather than to the histopathology of the tumor. The present knowledge of treatment is based on a total of 49 cases. Treatment of the solid form of SOT associated with the roots of the teeth by local curettage with removal of the adjacent teeth appears to be effective for the prevention of recurrence.

\section{References}

1. Philipsen HP and Reichart PA: Classification of odontogenic tumours. A historical review. J Oral Pathol Med 35: 525-529, 2006.

2. Barnes L, Eveson JW, Reichart P and Sidransky D (eds): WHO histological classification of odontogenic tumours. In: Pathology and Genetics of Head and Neck Tumours. IARC Press, Lyon, p284, 2005.

3. Perdigão PF, Gomez RS, Pimenta FJ and De Marco L: Ameloblastin gene (AMBN) mutations associated with epithelial odontogenic tumors: Oral Oncol 40: 841-846, 2004.

4. Pullon PA, Shafer WG, Elzay RP, Kerr DA and Corio RL: Squamous odontogenic tumor. Report of six cases of a previously undescribed lesion. Oral Surg Oral Med Oral Pathol 40: 616-630, 1975.

5. Reichart PA: Squamous odontogenic tumor. In: Pathology and Genetics of Head and Neck Tumours. Barnes L, Eveson JW, Reichart P, Sidransky D (eds). IARC Press, Lyon, p301, 2005.

6. Saxby MS, Rippin JW and Sheron JE: Case report: Squamous odontogenic tumor of the gingiva. J Periodontol 64: 1250-1252, 1993.

7. Philipsen HP and Reichart PA: Squamous odontogenic tumor (SOT): A benign neoplasm of the periodontium. A review of 36 reported cases. J Clin Periodontol 23: 922-926, 1996.

8. Kim K, Mintz SM and Stevens J: Squamous odontogenic tumor causing erosion of the lingual cortical plate in the mandible: A report of 2 cases. J Oral Maxillofac Surg 65: 1227-1231, 2007.

9. Reichart PA and Philipsen HP (eds): Squamous odontogenic tumor. In: Odontogenic Tumors and Allied Lesions. 1st edition. Quintessence Publishing, New Malden, Surrey, pp87-92, 2004.

10. Ruhin B, Raoul G, Kolb F, Casiraghi O, Lecomte-Houcke M, Ghoul S, Auriol M and Ferri J: Aggressive maxillary squamous odontogenic tumour in a child: Histological dilemma and adaptative surgical behaviour. Int J Oral Maxillofac Surg 36: 864-866, 2007

11. Clayman L: Odontogenic tumors. In: Holland-Frei Cancer Medicine. Kufe DW, Pollock RE, Weichselbaum RR, Bast RC Jr, Gansler TS, Holland JF and Frei E III $(e d s)$. 6th edition. BC Decker, Hamilton, ON, Chapter 91, 2003.

12. Cillo JE Jr, Ellis E III and Kessler HP: Pericoronal squamous odontogenic tumor associated with an impacted mandibular third molar: A case report. J Oral Maxillofac Surg 63: 413-416, 2005.

13. Haghighat K, Kalmar JR and Mariotti AJ: Squamous odontogenic tumor: Diagnosis and management. J Periodontol 73 653-656, 2002.

14. Hietanen J, Lukinmaa PL, Ahonen P, Krees R and Calonius PE: Peripheral squamous odontogenic tumour. Brit J Oral Maxillofac Surg 23: 362-365, 1985 .
15. Baden E, Doyle J, Mesa M, Fabié M, Lederman D and Eichen M: Squamous odontogenic tumor. Report of three cases including the first extraosseous case. Oral Surg Oral Med Oral Pathol 75: 733-738, 1993.

16. Ide F, Obara K, Mishima K, Saito I, Horie N, Shimoyama T and Kusama K: Peripheral odontogenic tumor: A clinicopathologic study of 30 cases. General features and hamartomatous lesions. J Oral Pathol Med 34: 552-557, 2005.

17. Malathi N, Radhika T, Thamizh $\mathrm{CH}$ and Nandakumar N: Peripheral squamous odontogenic tumor. Indian J Dent Res 23: 286-288, 2012.

18. Anneroth G and Hansen LS: Variations in keratinizing odontogenic cysts and tumors. Oral Surg Oral Med Oral Pathol 54: $530-546,1982$

19. Leider AS, Jonker LA and Cook HE: Multicentric familial squamous odontogenic tumor. Oral Surg Oral Med Oral Pathol 68: 175-181, 1989.

20. McNeill J, Price HM and Stoker NG: Squamous odontogenic tumor: Report of case with long-term history. J Oral Surg 38: 466-471, 1980.

21. van der Waal I, de Rijcke TB and van der Kwast WA: Possible squamous odontogenic tumor: Report of case. J Oral Surg 38: 460-462, 1980

22. Swan RH and McDaniel RK: Squamous odontogenic proliferation with probable origin from the rests of Malassez (early squamous odontogenic tumor?). J Periodontol 54: 493-496, 1983.

23. Doyle JL, Grodjesk JE, Dolinsky HB and Rafel SS: Squamous odontogenic tumor: Report of three cases. J Oral Surg 35: 994-996, 1977.

24. Leventon GS, Happonen RP and Newland JR: Squamous odontogenic tumor. Am J Surg Pathol 5: 671-677, 1981.

25. Ide F, Shimoyama T, Horie N and Shimizu S: Intraosseous squamous cell carcinoma arising in association with a squamous odontogenic tumour of the mandible. Oral Oncol 35: 431-434, 1999.

26. Tarsitano A, Agosti R and Marchetti C: The diagnostic and surgical management of a multifocal calcifiyng epithelial odontogenic tumor in the mandible and maxilla associated with a squamous odontogenic tumor: First reported case in the literature. Oral Surg Oral Med Oral Pathol 113: e6-e11, 2012.

27. Favia GF, Di Alberti L, Scarano A and Piattelli A: Squamous odontogenic tumour: Report of two cases. Oral Oncol 33: 451-453, 1997.

28. Goldblatt LI, Brannon RB and Ellis GL: Squamous odontogenic tumor. Report of five cases and review of the literature. Oral Surg Oral Med Oral Pathol 54: 187-196, 1982.

29. Hopper TL, Sadeghi EM and Pricco DF: Squamous odontogenic tumor. Report of a case with multiple lesions. Oral Surg Oral Med Oral Pathol 50: 404-410, 1980.

30. Mills WP, Davila MA, Beuttenmuller EA and Koudelka BM: Squamous odontogenic tumor. Report of a case with lesions in three quadrants. Oral Surg Oral Med Oral Pathol 61: 557-563, 1986.

31. Badni M, Nagaraja A and Kamath V: Squamous odontogenic tumor: A case report and review of literature. J Oral Maxillofac Pathol 16: 113-117, 2012.

32. Kristensen S, Andersen J and Jacobsen P: Squamous odontogenic tumour: Review of the literature and a new case. J Laryngol Otol 99: 919-924, 1985.

33. de Oliveira MG, Carrard VC, Danesi CC, Rados PV and Sant'Ana Filho M: Squamous odontogenic tumor: With recurrence and 12 years of follow-up. Rev Ciênc Méd, Campinas 16: 51-56, 2007.

34. Cataldo E, Less WC and Giunta JL: Squamous odontogenic tumor. A lesion of the periodontium. J Periodontol 54: 731-735, 1983.

35. Siar $\mathrm{CH}$, Nakano K, Ng KH, Tomida M, Nagatsuka H and Kawakami T: Squamous odontogenic tumor of the mandible: A case report demonstrating immunoexpression of Notch1, 3, 4, Jagged1 and Delta1. Eur J Medical Res 15: 180-184, 2010.

36. Carr RF, Carlton DM Jr and Marks RB: Squamous odontogenic tumor: Report of case. J Oral Surg 39: 297-298, 1981.

37. Norris LH, Baghaei-Rad M, Maloney PL, Simpson G and Guinta J: Bilateral maxillary squamous odontogenic tumors and the malignant transformation of a mandibular radiolucent lesion. J Oral Maxillofac Surg 42: 827-834, 1984.

38. Monteil RA and Terestri P: Squamous odontogenic tumor related to an unerupted lower canine. J Oral Maxillofac Surg 43: 888-895, 1985 . 
39. Warnock GR, Pierce GL, Correll RW and Baker DA Triangular-shaped radiolucent area between roots of the mandibular right canine and first premolar. J Am Dent Assoc 110: 945-946, 1985.

40. Tatemoto Y, Okada Y and Mori M: Squamous odontogenic tumor: Immunohistochemical identification of keratins. Oral Surg Oral Med Oral Pathol 67: 63-67, 1989.

41. Yaacob HB: Squamous odontogenic tumor. J Nihon Univ Sch Dent 32: 187-191, 1990.

42. Reichart PA and Philipsen HP: Squamous odontogenic tumor. J Oral Pathol Med 19: 226-228, 1990.

43. Schwartz-Arad D, Lustmann J and Ulmansky M: Squamous odontogenic tumor. Review of the literature and case report. Int J Oral Maxillofac Surg 19: 327-330, 1990.

44. Kusama K, Kawashima A, Nagai H, Tajima M, Tsuchiya H, Yamaguchi H, Furuya M, Terakado M, Sato H and Moro I: Squamous odontogenic tumor of the maxilla: Report of a case. J Oral Sci 40: 119-122, 1998.
45. Barrios TJ, Sudol JC and Cleveland DB: Squamous odontogenic tumor associated with an erupting maxillary canine: Case report. J Oral Maxillofac Surg 62: 742-744, 2004.

46. Agostini T, Sacco R, Bertolai R, Acocella A, Colafranceschi M and Lazzeri D: Peri-implant squamous odontogenic tumor. J Craniofac Surg 22: 1151-1157, 2011.

47. Jones BE, Sarathy AP, Ramos MB and Foss RD: Squamous odontogenic tumor. Head Neck Pathol 5: 17-19, 2011.

48. Bansal S and Joshi SK: Squamous odontogenic tumor with unusual localization and appearance: A rare case report. Case Rep Med 2013: 4077967, 2013.

49. Pant H and Pathak S: Case Report: Squamous odontogenic tumor-exceedingly rare neoplasm. Indian Journal of Basic \& Applied Medical Research 2: 1023-1026, 2013. 